COVID-19

\title{
Impact of COVID-19 restrictions on hospitalisation and post-operative rehabilitation of head and neck cancer patients
}

\author{
L'impatto delle restrizioni da COVID-19 sulla degenza e la riabilitazione post-operatoria \\ dei pazienti con carcinoma cervico-cefalico
}

\author{
Erika Crosetti ${ }^{1}$, Martina Tascone ${ }^{1}$, Giulia Arrigoni ${ }^{1}$, Marco Fantini ${ }^{1}$, Giovanni Succo ${ }^{1,2}$ \\ ${ }^{1}$ Head and Neck Oncology Unit, Candiolo Cancer Institute, FPO-IRCCS, Candiolo (TO), Italy; ${ }^{2}$ Department of Oncology, University \\ of Turin, Orbassano (TO), Italy
}

\section{SUMMARY}

Objective. The COVID-19 pandemic emergency forced the health system in Italy to implement an immediate reorganisation to support the care of tens of thousands of patients and to maintain the quality of care for patients with other pathologies, such as oncologic diseases. The main goal of this study was to evaluate the impact of COVID-19 restrictions on the hospitalisation and post-operative rehabilitation of head and neck oncologic patients and to determine whether the introduction of new technologies such as video-communication may be useful to mitigate social distancing by close family members.

Methods. Fifty-one consecutive patients underwent surgery for head and neck cancer during the period of lockdown caused by the COVID-19 pandemic. The data collected (postoperative pain, post-operative complications, duration of hospitalisation) were compared with those of 51 consecutive patients treated for head and neck cancer in the period immediately preceding lockdown.

Results. The average duration of hospitalisation was longer in patients operated on in the COVID-19 period, and, in particular, among patients who underwent a more demanding rehabilitation protocol. Despite this, our study did not show a significant difference in psychological aspects during hospitalisation.

Conclusions. The greatest difficulties that occurred in the COVID-19 period were met by a greater commitment from medical staff, allowing the quality of life of head and neck cancer patients during post-operative rehabilitation to be maintained at a similar level to that before the pandemic. In the future, there will be a need for technological solutions to bring the patient closer to family members.

KEY WORDS: COVID-19, head neck cancer, rehabilitation

\section{RIASSUNTO}

Obiettivo. L'emergenza causata dalla pandemia da COVID-19 ha costretto il sistema sanitario italiano ad attuare un'immediata riorganizzazione per supportare la cura di decine di migliaia di pazienti e mantenere la qualità delle cure di pazienti con altre patologie, quali le malattie oncologiche. L'obiettivo principale di questo studio è stato quello di valutare l'impatto delle restrizioni da COVID-19 sulla degenza e sulla riabilitazione post-operatoria di pazienti oncologici testa-collo e determinare se l'introduzione di nuove tecnologie, come la videocomunicazione, possa essere utile per mitigare il distanziamento sociale dai familiari stretti.

Metodi. Durante il periodo di lockdown causato dalla pandemia da COVID-19, 51 pazienti consecutivi sono stati sottoposti a intervento chirurgico per tumori maligni testa-collo. I dati raccolti (dolore post-operatorio, complicanze post-operatorie, durata della degenza) sono stati confrontati con quelli di 51 pazienti consecutivi trattati per tumori maligni testacollo nel periodo immediatamente precedente il lockdown.

Risultati. La durata media della degenza è stata più lunga nei pazienti operati nel periodo del COVID-19, in particolare nei pazienti sottoposti a un protocollo riabilitativo più impegnativo. Nonostante ciò, il nostro studio non ha dimostrato una differenza significativa negli aspetti psicologici durante il ricovero.
Received: April 7, 2021

Accepted: September 13, 2021

\section{Correspondence}

Erika Crosetti

Head and Neck Oncology Unit, FPO-IRCCS, Candiolo Cancer Institute, 10060 Candiolo, Turin, Italy Tel. + 390119933663

E-mail: erika.crosetti@ircc.it

\section{Funding}

This research was funded by: Regione Piemonte, Progetto A Funzione (years 2019-2021); FPRC 5x1000 2016 Ministero della Salute Progetto ARDITE - BioHeNeC; Fondi Ricerca Corrente 2021, Ministero della Salute.

Conflict of interest

The Authors declare no conflict of interest.

How to cite this article: Crosetti E, Tascone M, Arrigoni G, et al. Impact of COVID-19 restrictions on hospitalisation and post-operative rehabilitation of head and neck cancer patients. Acta Otorhinolaryngol Ital 2021;41:489-495. https:// doi.org/10.14639/0392-100X-N1604

() Società Italiana di Otorinolaringoiatria e Chirurgia Cervico-Facciale

\section{(c) (1) $(2)$}

This is an open access article distributed in accordance with the CC-BY-NC-ND (Creative Commons Attribution-NonCommercial-NoDerivatives 4.0 International) license. The article can be used by giving appropriate credit and mentioning the license, but only for non-commercial purposes and only in the original version. For further information: https:// creativecommons.org/licenses/by-nc-nd/4.0/deed.en 
Conclusioni. Le maggiori difficoltà che si sono incontrate nel periodo del COVID-19 sono state superate da un maggiore impegno da parte di tutto il personale sanitario, consentendo di mantenere la qualità di vita dei pazienti a un livello simile a quello precedente la pandemia. In futuro, saranno necessarie soluzioni tecnologiche per avvicinare il paziente ai familiari.

PAROLE CHIAVE: COVID-19, carcinoma testa-collo, riabilitazione

\section{Introduction}

The emergency caused by the Severe Acute Respiratory Syndrome Coronavirus 2 (SARS-CoV-2) pandemic forced the health system in Italy to implement an immediate reorganisation to support the care of tens of thousands of Coronavirus Disease 2019 (COVID-19) patients and at the same time to maintain the quality of care for patients with other pathologies ${ }^{1-3}$. Diverting the attention of the healthcare system to focus on overcoming the pandemic has increased the risk of overlooking other important and urgent pathologies, such as oncologic ones ${ }^{4}$. Indeed, oncologic patients have a more severe treatment to face and overcome, from both physical and psychological points of view ${ }^{5}$, and especially those affected by head and neck cancer. Head and neck oncologic surgical procedures are considered to be onerous treatments with a severe impact on physical, functional and psychological domains; post-operative recovery involves rehabilitation of important functions from both physical and social perspectives (swallowing, verbal communication, breathing) ${ }^{6,7}$. In the rehabilitation period, a fundamental role is played not only by healthcare staff, but also by caregivers. Relatives and close family members offer the patient important psychological and motivational support when it is often difficult to face the disease in a positive and rational way. For this reason, in the normal pre-pandemic situation, the caregiver can be present during the hospitalisation period and this is highly recommended for motivational reinforcement of the patient. This support was lost during the COVID-19 pandemic, which forced the adoption of strict rules to counter the spread of viral infection, including banning caregivers from entering hospitals. This situation meant that the oncologic patient had to endure the treatment process without the important psychological support of a family member.

The main goal of this study was to evaluate the impact of COVID-19 restrictions on hospitalisation and post-operative rehabilitation of head and neck oncologic patients and to determine whether the introduction of new technologies such as video-communication may be useful to mitigate social distancing by close family members.

\section{Materials and methods}

This study evaluated 51 consecutive patients (35 males and 16 females, age (mean $\pm \mathrm{SD}$ ) $65.4 \pm 14.1$ years) who underwent surgery for head and neck cancers. All patients were treated at the Head and Neck Oncological Unit of the FPO IRCCS, Candiolo Cancer Institute, Turin, Italy in the period of lockdown caused by the COVID-19 pandemic (March-June 2020). During this period, only non-deferrable surgical procedures were carried out.

The study received approval from the Committee of Ethics in Research in our hospital. All of the procedures were considered to be conventional in terms of technique and indications, in accordance with current guidelines and therefore also in accordance with the ethical standards of the Institutional and/or National Research Committee and with the 1964 Helsinki Declaration and its later amendments.

During the health emergency caused by the COVID-19 pandemic, entry into our hospital by any person was regulated by triage: measurement of external body temperature, hand sanitisation and wearing a surgical mask. Access was only allowed to patients and in the case of non-self-sufficient patients access was also restricted to a single caregiver. All oncologic patients were hospitalised the day before surgery to collect a nasopharyngeal swab for SARS-CoV-2 RNA and a chest X-ray. Patients remained hospitalised in a dedicated isolation ward awaiting their results. If both tests (nasopharyngeal swab and chest X-ray) were negative, patients were transferred to the ward in the afternoon.

During the patients' period of hospitalisation, no relative was admitted to the ward, except for non-self-sufficient patients (11 patients in the pre-COVID-19 period and 5 patients in the COVID-19 period), for whom the presence of a caregiver was mandatory. For the same reason, patients were not allowed to leave the ward.

The following data were collected: post-operative pain (Visual Analog Scale (VAS) scores), post-operative complications and duration of hospitalisation. Furthermore, at the end of the hospitalisation period, patients completed the Hospital Anxiety and Depression Scale (HADS) questionnaire ${ }^{8,9}$. The Hospital Anxiety and Depression Scale (HADS) is a self-report questionnaire designed to assess anxiety and depressive states in hospitalised patients. The HADS uses two scales of 7 questions each. One scale assesses the anxiety component and the other the depression component. The HADS Scale is useful to identify patients with mood disorders. A maximum score of 21 can be obtained for each scale of the questionnaire. Patients scoring between 0 and 7 are indicated as normal, those scoring be- 
tween 8 and 10 are indicated as at-risk of developing mood disorders (borderlines), while patients scoring above 10 are indicated as full cases.

This data were compared with that of 51 consecutive pa- tients (40 males and 11 females, mean age 66.0 years, SD 14.6) treated for head neck cancers in the period immediately preceding lockdown (September 2019 - January 2020) (Tabs. I-III).

Table I. Demographic characteristics of patients treated in the pre-COVID-19 and COVID-19 periods.

\begin{tabular}{|c|c|c|c|}
\hline Characteristics & $\begin{array}{l}\text { Pre-COVID-19 period } \\
\text { No. of patients }(\%)\end{array}$ & $\begin{array}{l}\text { COVID-19 period } \\
\text { No. of patients }(\%)\end{array}$ & $p$-value \\
\hline Age, years & & & 0.695 \\
\hline Mean & 66 & 65 & \\
\hline Range & $16-87$ & $20-89$ & \\
\hline Sex & & & 0.370 \\
\hline Male & $40(78)$ & $35(69)$ & \\
\hline Female & $11(22)$ & $16(31)$ & \\
\hline Pre-treated patient & & & 0.091 \\
\hline No & $44(86)$ & $36(71)$ & \\
\hline Yes & $7(14)$ & $15(29)$ & \\
\hline Non-self-sufficient patients & & & 0.172 \\
\hline No & $40(78)$ & $46(90)$ & \\
\hline Yes & $11(22)$ & $5(10)$ & \\
\hline Tumour site & & & 0.806 \\
\hline Neck (CUP, skin cancers) & $13(25)$ & $14(27)$ & \\
\hline Oral cavity and oropharynx & $16(31)$ & $16(31)$ & \\
\hline Larynx and hypopharynx & $15(29)$ & $17(33)$ & \\
\hline Salivary glands & $7(14)$ & $4(8)$ & \\
\hline Type of surgery & & & 0.468 \\
\hline Without reconstruction & $40(78)$ & $35(69)$ & \\
\hline With reconstruction & $11(22)$ & $16(31)$ & \\
\hline Pedicled flap & $6(12)$ & $11(22)$ & \\
\hline Free flap & $5(10)$ & $5(10)$ & \\
\hline Tracheostomy & & & $>0.999$ \\
\hline No & $25(49)$ & $25(49)$ & \\
\hline Yes & $26(51)$ & $26(51)$ & \\
\hline NGT & & & 0.216 \\
\hline No & $36(71)$ & $29(57)$ & \\
\hline Yes & $15(29)$ & $22(43)$ & \\
\hline \multicolumn{4}{|c|}{ Dindo classification of surgical complications } \\
\hline I & $1(2)$ & $1(2)$ & \\
\hline$\|$ & $0(0)$ & $2(4)$ & \\
\hline IIla & $0(0)$ & $1(2)$ & \\
\hline$\| l l b$ & $2(4)$ & $6(12)$ & \\
\hline $\mathrm{IVa}$ & $0(0)$ & $0(0)$ & \\
\hline $\mathrm{IVb}$ & $0(0)$ & $0(0)$ & \\
\hline V & $0(0)$ & $0(0)$ & 0.072 \\
\hline \multicolumn{4}{|l|}{ Duration of hospitalisation } \\
\hline$\leq 7$ days & $27(53)$ & $28(55)$ & 0.281 \\
\hline$>7$ days & $24(47)$ & $23(45)$ & \\
\hline
\end{tabular}

CUP: carcinoma of unknown primary (origin); NGT: nasogastric tube. 
E. Crosetti et al.

Table II. Tumour staging of patients treated in the pre-COVID-19 and COVID-19 periods.

\begin{tabular}{|c|c|c|c|}
\hline Tumour site & $\begin{array}{l}\text { Pre-COVID-19 period } \\
\text { No. of patients }(\%)\end{array}$ & $\begin{array}{l}\text { COVID-19 period } \\
\text { No. of patients (\%) }\end{array}$ & $p$-value \\
\hline Neck (CUP, skin cancers) & & & 0.759 \\
\hline Stage I & $4(8)$ & $2(4)$ & \\
\hline Stage III & $4(8)$ & $6(12)$ & \\
\hline Stage IVA & $2(4)$ & $2(4)$ & \\
\hline Stage IVB & $3(6)$ & $4(8)$ & \\
\hline Stage I & $6(12)$ & $8(16)$ & \\
\hline Stage II & $4(8)$ & $4(8)$ & \\
\hline Stage III & $1(2)$ & $1(2)$ & \\
\hline Stage IVA & $3(6)$ & $2(4)$ & \\
\hline Stage IVB & $2(4)$ & $1(2)$ & \\
\hline Stage III & $4(8)$ & $4(8)$ & \\
\hline Stage IVA & $2(4)$ & $4(8)$ & \\
\hline Stage IVB & $3(6)$ & $3(6)$ & \\
\hline Salivary glands & & & 0.284 \\
\hline Stage I & $1(2)$ & $2(4)$ & \\
\hline Stage II & $2(4)$ & $2(4)$ & \\
\hline Stage III & $1(2)$ & $0(0)$ & \\
\hline Stage IVA & $3(6)$ & $0(0)$ & \\
\hline
\end{tabular}

CUP: carcinoma of unknown primary (origin).

Table III. Hospital Anxiety and Depression Scale and Visual Analogue Scale scores of patients treated in the pre-COVID-19 and COVID-19 periods.

$\begin{array}{lcc}\text { Characteristics } & \begin{array}{c}\text { Pre-COVID-19 period } \\ \text { No. of patients (\%) }\end{array} & \begin{array}{c}\text { COVID-19 period } \\ \text { No. of patients (\%) }\end{array} \\ \begin{array}{l}\text { HADS score (anxiety scale) } \\ \leq 7\end{array} & 38(75) & 43(84) \\ 8-10 & 7(14) & 3(6) \\ >10 & 6(12) & 5(10) \\ \text { HADS score (depression scale) } & & 40(78) \\ \leq 7 & 41(80) & 7(14) \\ 8-10 & 8(16) & 4(8) \\ >10 & 2(4) & 20(39) \\ \text { VAS score } & & 17(33) \\ 0 & 21(41) & 12(24) \\ 1 & 13(25) & 1(2) \\ 2 & 12(24) & 1(2) \\ 3 & 1(2) & 0.652 \\ 4 & 3(6) & 0.739 \\ >4 & 1(2) & (0)\end{array}$

HADS: Hospital Anxiety and Depression Scale; VAS: Visual Analogue Scale. 
Statistical analysis was carried out with GraphPad Prism software (Version 7.0, GraphPad Software, Inc, San Diego, CA). The D'Agostino-Pearson normality test was used to verify Gaussian distributions of continuous variables. Means, ranges and standard deviations were calculated for continuous variables. Fisher exact tests and Chi-square tests were used to compare categorical variables, while Mann Whitney tests were used to compare continuous variables, since none of the tested variables passed the normality test. An alpha of 0.05 was considered for statistical procedures.

\section{Results}

No significant differences were found concerning age, gender distribution, tumour site and stage, type of surgery, number of positioned NGTs and tracheostomies between the groups of before and after the COVID-19 period (Tabs. I-II). The duration of hospitalisation for patients who underwent head and neck surgery during the lockdown ranged from 3-91 days with a mean of $12.9 \pm 14.4$ days, whereas for patients operated in the pre-COVID-19 period, the range was 2-23 days with a mean of $9.0 \pm 5.7$ days. The average duration of hospitalisation was longer in patients operated on in the COVID-19 period, considering both the tumour location and type of surgery, even if no significant difference was found between groups. Additionally, considering patients who required a more demanding rehabilitation protocol, duration of hospitalisation was found significantly longer for the group during the COVID-19 period, with a mean hospital stay of $25.1 \pm 19.3$ days ( $95 \%$ confidence interval: 14.5-35.8 days) compared to a mean hospital stay of $15.3 \pm 3.9$ days ( $95 \%$ confidence interval: 13.1-17.4 days) for the pre-COVID-19 period (Fig. 1).

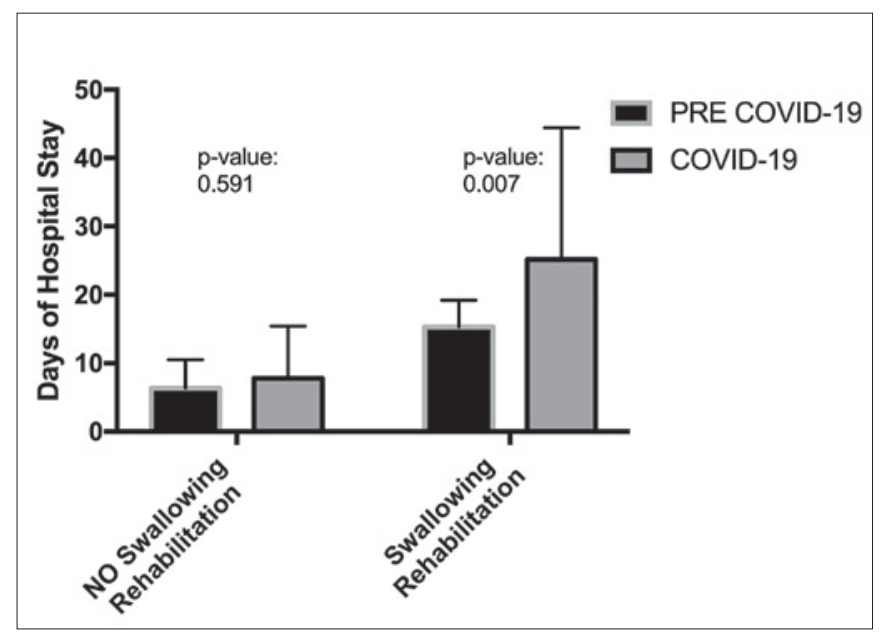

Figure 1. Mean duration of post-operative hospitalisation for patients who required swallowing rehabilitation or less demanding rehabilitation.
The mean value for post-operative pain verified with the Visual Analog Scale (VAS) score did not show a significant difference between the COVID-19 period and pre-COVID-19 period (Tab. III).

Complications were classified according to the Dindo classification of surgical complications ${ }^{10}$. Post-operative complications were higher in patients operated on during the COVID-19 period: $10 v s$ 3. Nonetheless, no significant difference was found between groups.

The HADS questionnaire did not report a significant difference before and during the COVID-19 period (mean score on depression scale of $5.0 \pm 3.1$ and $5.2 \pm 4.1$, respectively; mean score on anxiety scale of $5.3 \pm 3.8$ and $5.3 \pm 3.5$, respectively) (Tab. III). For the 11 non-sufficient patients admitted with a caregiver in the pre-COVID-19 period and the 5 patients in the COVID-19 period, the mean scores on the depression scale were $6.9 \pm 2.4$ and $7.2 \pm 8.1$, respectively; the mean scores on the anxiety scale were $6.2 \pm 2.0$ and $6.8 \pm 5.9$, respectively.

\section{Discussion}

In Italy, restrictions on access to hospitals imposed by the COVID-19 pandemic have undoubtedly made head and neck post-operative rehabilitation more difficult ${ }^{11}$. Patients were not allowed to leave the ward, they were alone, and lacked the possibility of distraction from a psychologically stressful situation caused by the illness and the physical difficulties they faced. Generally, in the post-operative period, head and neck patients can walk, but unfortunately, this activity was drastically limited during the pandemic.

It is well known that, in normal times, the role of caregivers is fundamental not only in assisting patients, but also in supporting and encouraging them during rehabilitation. A delicate phase during the post-operative period in head and neck oncology is rehabilitation of swallowing and resumption of oral intake ${ }^{12-14}$. The speech therapist instructs the patient for several hours every day, but rehabilitation exercises must also be carried out during the rest of the day. In normal times, the caregiver is instructed in the appropriate exercises required and this makes a significant difference in helping the patient to carry out these exercises correctly during meals.

Assistance from the caregiver also stimulates rehabilitation of verbal and non-verbal communication, a function that is difficult to practice alone. Furthermore, post-operatively, most head and neck patients can only communicate nonverbally; this makes it very difficult to stay in touch with family members who cannot be physically present close to the patient. Hospitalisation is also more psychologically stressful if the patient can no longer communicate verbally 
and when there is no support from a family member who can reassure him/her.

This particular situation prompted the medical staff to try to fill these care gaps during the COVID-9 period, paying more attention to oncologic patients than they normally would in the non-COVID period, and to aspects that are normally entrusted to caregivers.

In our study, the results show that the percentage of postoperative complications was higher in the group of patients operated in the COVID-19 period compared with the pre-COVID19 period (10 vs 3 patients, respectively). A selection bias could be attributed to the greater number of critically-ill patients who underwent surgery during the period of reorganisation of health activities caused by the pandemic. In fact, hospitals were only allowed to operate on non-deferrable cases.

Patients are generally discharged when they are self-sufficient from a swallowing and respiratory perspective. The increase in average duration of hospitalisation (13 vs 9 days) is a consequence of the rehabilitation difficulties caused by COVID-19 restrictions and patient isolation encountered in the post-operative period. The difference in length of hospitalisation was more evident for patients who had to undergo a more demanding operation, which required more intensive rehabilitation. Despite this, our study did not show a significant difference in psychological aspects during hospitalisation before and during the pandemic.

The HADS evaluation substantially reported the same mean score for the two groups. A HADS score of about 5 is considered normal for both the depression and anxiety scales. During the SARS-CoV-2 pandemic, several efforts were made to maintain the quality of care by paying greater attention to the psychological sphere of patients and family members. Both patients and their families experienced a more difficult and stressful period which, in addition to the problems caused by the head and neck disease, has also seen the introduction of social distancing, restrictions on access to hospital, and fear of SARSCoV-2 infection. For this reason, medical staff updated family members daily on the condition of patients, and nurses organised a video call every two days between family members and patients who were unable to do so themselves. All of the medical staff were more involved in maintaining the quality of hospitalisation and post-operative rehabilitation, and at the same time trying to ease the anxiety of patients and their families.

On the basis of these preliminary data, to date, caregivers can assist patients in the period commencing after preoperative collection of the pharyngeal swab through postoperative periods of hospitalisation of more than 7 days.

\section{Conclusions}

The COVID-19 pandemic has forced cancer patients to endure the treatment process without the important psychological support of a caregiver, especially during postoperative recovery. This particular situation has resulted in an increase in duration of hospitalisation, particularly for patients who require more demanding post-operative rehabilitation. Nevertheless, the HADS score did not report a worse psychological situation from hospitalisation during COVID-19 restrictions.

The greatest difficulties that occurred in the COVID-19 period were met by a greater commitment from all medical staff. Thanks to this, during the pandemic, it was possible to maintain the quality of life of head and neck cancer patients during post-operative rehabilitation at a similar level to that before the pandemic.

This study highlights the fact that, in future, there is a need for technological solutions to bring the patient closer to family members, particularly when those members cannot be physically present.

\section{References}

1 Ansarin M. Surgical management of head and neck tumours during the SARS-CoV (COVID-19) pandemic. Acta Otorhinolaryngol Ital 2020;40:87-89. https://doi.org/10.14639/0392-100X-N0783

2 Balasubramanyam A, Mithun S, Rani G, et al. Otolaryngology surgical activity in tertiary care center during the COVID-19 lockdown. Indian J Otolaryngol Head Neck Surg 2020;Oct 1:1-6. https://doi. org/10.1007/s12070-020-02155-7

3 Ralli M, Mannelli G, Bonali M, et al. Impact of COVID-19 on otolaryngology in Italy: a commentary from the COVID-19 task force of the Young Otolaryngologists of the Italian Society of Otolaryngology. Eur Rev Med Pharmacol Sci 2020;24:7516-7518. https://doi. org/10.26355/eurrev_202007_21925

4 Brody RM, Albergotti WG, Shimunov D, et al. Changes in head and neck oncologic practice during the COVID-19 pandemic. Head Neck 2020;42:1448-1453. https://doi.org/10.1002/hed.26233

5 Clerici CA, Massimino M, Ferrari A. On the clinical psychologist's role in the time of COVID-19, with particular reference to experience gained in pediatric oncology. Psychooncology 2020;29:1374-1376. https://doi.org/10.1002/pon.5418

6 Vergara J, Starmer HM, Wallace S, et al. Swallowing and communication management of tracheostomy and laryngectomy in the context of COVID-19: a review. JAMA Otolaryngol Head Neck Surg 2021;147:85-90. https://doi.org/10.1001/jamaoto.2020.3720

7 Mitchell O, Durrani A, Price R. Rehabilitation of patients following major head and neck cancer surgery. Br J Nurs 2012;21:S31-S37. https://doi.org/10.12968/bjon.2012.21.Sup10.S31

8 Snaith RP. The hospital anxiety and depression scale. Health Qual Life Outcomes 2003;1:29. https://doi.org/10.1186/1477-7525-1-29

9 Annunziata MA, Muzzatti B, Bidoli E, et al. Hospital Anxiety and Depression Scale (HADS) accuracy in cancer patients. Support Care Cancer 2020;28:3921-3926. https://doi.org/10.1007/s00520-019-05244-8

10 Dindo D, Demartines N, Clavien PA. Classification of surgical complications: a new proposal with evaluation in a cohort of 6336 pa- 
tients and results of a survey. Ann Surg 2004;240:205-213. https://doi. org/10.1097/01.sla.0000133083.54934.ae

11 Galli J, Settimi S, Tricarico L, et al. Clinical and surgical management of patients with head and neck cancer in a COVID-19 dedicated center in Italy. Head Neck 2020;42:1466-1470. https://doi.org/10.1002/ hed.26263

12 Clarke P, Radford K, Coffey M, et al. Speech and swallow rehabilitation in head and neck cancer: United Kingdom National Multidisciplinary Guidelines. J Laryngol Otol 2016;130(S2):S176-S180. https://doi.org/10.1017/S0022215116000608
13 Magaldi L, Salzo AE, Trecca EMC, et al. The importance of head and neck counselling in the COVID-19 era. Apulian Working Group. Acta Otorhinolaryngol Ital 2021;41:192-194. https://doi. org/10.14639/0392-100X-N0941

14 Mannelli G, Ralli M, Bonali M, et al. Impact of COVID-19 pandemic on Italian Otolaryngology Units: a nationwide study. Acta Otorhinolaryngol Ital 2020;40:325-331. https://doi. org/10.14639/0392-100X-N0832 